\title{
High-dose and combination antipsychotic prescribing in acute adult wards in the UK: the challenges posed by p.r.n. prescribing
}

Carol Paton, Thomas R. E. Barnes, Mary-Rose Cavanagh, David Taylor and Paul Lelliott, on behalf of the POMH-UK project team

\section{Background}

Clinical guidelines recommend the routine use of a single antipsychotic drug in a standard dose, but prescriptions for high-dose and combined antipsychotics are common in clinical practice.

\begin{abstract}
Aims
To evaluate the effectiveness of a quality improvement programme in reducing the prevalence of high-dose and combined antipsychotic prescribing in acute adult in-patient wards in the UK.
\end{abstract}

\section{Method}

Baseline audit was followed by feedback of benchmarked data and delivery of a range of bespoke change interventions, and then by a further audit 1 year later

\section{Results}

Thirty-two services participated, submitting data for 3942 patients at baseline and 3271 patients at the 1-year audit.
There was little change in the prevalence of high-dose (baseline 36\%; re-audit 34\%) or combined antipsychotic prescribing (baseline 43\%; re-audit 39\%). As required ('p.r.n.') prescriptions were the principal cause of both high-dose and combined antipsychotic prescribing on both occasions.

\section{Conclusions}

The quality improvement programme did not have a demonstrable impact on prescribing practice in the majority of services. Future efforts to align practice with clinical guidelines need to specifically target the culture and practice of p.r.n. prescribing.

\section{Declaration of interest}

C.P., T.B. and D.T. have acted as consultants to pharmaceutical companies marketing antipsychotic medication; P.L., D.T. and T.B. have received funding from pharmaceutical companies for research studies. Other funding detailed in Acknowledgements.
There is no convincing evidence that combined antipsychotics are more effective than a single antipsychotic. ${ }^{1}$ Also, combining antipsychotics is a major cause of high-dose prescribing, ${ }^{2}$ an increased side-effect burden, ${ }^{1}$ and possibly increased mortality. ${ }^{3}$ Thus, evidence-based treatment guidelines for schizophrenia recommend antipsychotic monotherapy in standard dosage. ${ }^{4,5}$ Despite this, cross-sectional surveys consistently find that $40-50 \%$ of people receiving psychiatric in-patient treatment are prescribed combined antipsychotics. ${ }^{2,6}$ We report on a quality improvement initiative to reduce the prevalence of high-dose and combination antipsychotic prescribing in acute adult and psychiatric intensive care wards in the UK.

\section{Method}

All National Health Service (NHS) trusts and private healthcare organisations in the UK that provide specialist mental health services were invited to participate in a quality improvement project by the UK Prescribing Observatory for Mental Health $(\mathrm{POMH})$, focusing on high-dose and combination antipsychotic prescribing in acute adult psychiatric wards. Services that chose to participate were invited to send a project team to a workshop to discuss and review the aims, objectives and methodology of the project. The study consisted of three distinct phases: a baseline audit of prescribing practice with feedback of the benchmarked data to each participating service; the delivery of quality improvement interventions to trust teams; and then a further audit of prescribing practice 1 year after the baseline audit. The audit standards and three phases of the project are described.

\section{Audit standards}

Three standards were derived from treatment guidelines and consensus statements. First, the daily dose of an individual antipsychotic should be within licensed limits or, if a combination of antipsychotics is prescribed, the cumulative dose using the percentage method should not exceed $100 \%$. $^{7}$ Second, a single antipsychotic should be prescribed; exceptions are patients who are switching from one antipsychotic to another and those who have derived insufficient benefit from clozapine monotherapy. ${ }^{4}$ Finally, first-generation (typical) and second-generation (atypical) antipsychotic drugs should not be prescribed concurrently; exceptions are patients who are switching from one antipsychotic to another. $^{8}$

\section{Phase 1: baseline audit of prescribing practice}

Participating services were asked to submit data for all patients who, on a given census day during January 2006, occupied a bed on an acute adult or psychiatric intensive care ward and were being prescribed one or more antipsychotic drugs. The following data were collected for each patient: demographic variables (age, gender, ethnicity), clinical variables (ICD-10 diagnostic grouping, ${ }^{9}$ Mental Heath Act status); names and doses of all regular and pro re nata (p.r.n., or 'as required') antipsychotic drugs prescribed. The maximum prescribed dose that could be administered over a 24-h period was recorded, irrespective of whether it was administered or not. For patients who were prescribed more than one antipsychotic, the primary reason for the combination (as determined by the clinical team) was recorded. Data were entered on a web-based form and submitted through a secure web system. 


\section{Phase 2: delivery of quality improvement interventions}

Following the baseline audit, nine change interventions were developed and made available to participating services (further information is presented in a data supplement to the online version of this paper). All interventions were informed by the findings of the baseline audit. The interventions were of a type that research evidence has suggested has some effect on changing the behaviour of individuals working in healthcare settings. ${ }^{10}$ Participating trusts were encouraged to disseminate the audit report and interventions as widely as possible, and present the audit findings to local clinicians. The precise implementation strategy was determined by each trust's local POMH project team.

\section{Phase 3: re-audit of prescribing practice}

Data collection, as described for phase 1 , was repeated 1 year after the baseline audit. The census day was in January 2007.

\section{Data analysis}

Data from the baseline audit were analysed at national level to allow the characteristics of the whole sample to be described; simple descriptive statistics were used. For patients with a diagnosis of schizophrenia or related disorder (ICD-10 categories F20-29), a binary logistic regression analysis was conducted with high dose as the dependent variable, and combined antipsychotics and variables that have previously been shown to be associated with high dose $^{11}$ as the independent variables: age band, ward type, Mental Health Act status and gender. Data were further analysed at service level, to allow comparison of the findings against other services and the national data. Finally, data were analysed at ward level, allowing participating wards to compare themselves with their service as a whole and the national data. All analyses were repeated using the data from the second audit. Only the national data are described here. Data were analysed using SPSS version 14 for Windows.

\section{Results}

Thirty-two services, all of them NHS, participated in the baseline audit, submitting data for 3492 patients from 218 wards. All 32 services participated in the second audit, submitting data for 3271 patients from 209 wards. The demographic and clinical variables of patients occupying a bed at the point of the second audit did not differ from those of patients who occupied a bed during the baseline audit (Table 1).

\section{Prescribing practice compared with audit standards}

Table 2 summarises the extent to which prescribing practice deviated from the three audit standards at baseline and follow-up. For all three standards, and on both occasions, standards were not met for a substantial minority of patients. There was no meaningful change in prescribing practice between the two audits.

\section{Reasons for prescribing combined antipsychotics}

Of the 1503 patients prescribed combined antipsychotics in the baseline audit, the clinical team reported that the reason for this was to control disturbed behaviour in $683(45 \%)$ cases, because of a poor response to antipsychotic monotherapy in 259 (17\%) cases, to cover a period of acute positive symptom exacerbation in $183(12 \%)$ of cases and because the patient was switching from one antipsychotic to another in $125(8 \%)$ cases. For 142 (9\%) patients, the clinical team was unsure of the reason. In 56
(22\%) of the 259 cases where the reason given was poor response to monotherapy, the combination included clozapine.

At the 1-year audit, 1287 patients were prescribed combined antipsychotics; 489 (38\%) for the control of disturbed behaviour, $195(15 \%)$ for a period of acute positive symptom exacerbation, $192(15 \%)$ because of a poor response to antipsychotic monotherapy and $144(11 \%)$ because they were switching from one antipsychotic to another. For $131(10 \%)$ patients the clinical team was unsure of the reason or no reason was given. In 56 (29\%) of the 192 cases where the reason given was poor response to monotherapy, the combination included clozapine.

\section{Uptake of quality improvement interventions}

All participating services received a copy of the audit report benchmarking their organisation as a whole and their individual wards against the total national sample. (Details of the number of services that ordered copies of the quality improvement interventions are presented in the data supplement to the online version of this paper.)

\section{Predictors of high-dose and combination antipsychotic prescribing}

Combined antipsychotics were the major cause of high-dose prescribing at baseline and re-audit; at baseline, $8.8 \%$ of prescriptions for a single antipsychotic were for a high dose and $72.6 \%$ of prescriptions for combined antipsychotics were for a high dose. At re-audit these figures were $9.4 \%$ and $72.5 \%$ respectively. On both occasions the majority of prescriptions for combined antipsychotics were due to p.r.n. prescribng. Figure 1 shows the contribution of p.r.n. to high-dose prescribing. At baseline, $78.5 \%$ of prescriptions for combined first- and second-generation antipsychotics included p.r.n.. At re-audit, this proportion was $72.9 \%$.

\begin{tabular}{|c|c|c|}
\hline Demographic characteristics & $\begin{array}{l}\text { Baseline sample } \\
\qquad(n=3492)\end{array}$ & $\begin{array}{l}\text { Re-audit sample } \\
\qquad(n=3271)\end{array}$ \\
\hline $\begin{array}{l}\text { Gender, \% } \\
\text { Male }\end{array}$ & 57 & 58 \\
\hline $\begin{array}{l}\text { Ethnicity, \% } \\
\text { White/White British } \\
\text { Black/Black British } \\
\text { Asian } \\
\text { Mixed' or 'other' } \\
\text { 'Not stated', 'refused' or 'not } \\
\text { collected' }\end{array}$ & $\begin{array}{r}68 \\
14 \\
6 \\
7 \\
5\end{array}$ & $\begin{array}{r}68 \\
15 \\
7 \\
7 \\
3\end{array}$ \\
\hline $\begin{array}{l}\text { Age, years } \\
\text { Mean (s.d.) } \\
\text { Range }\end{array}$ & $\begin{array}{c}41(17) \\
17-71\end{array}$ & $\begin{array}{c}41(13) \\
17-77\end{array}$ \\
\hline $\begin{array}{l}\text { ICD-10 diagnosis, \% } \\
\text { F20-29 (schizophrenia } \\
\text { or related disorder) } \\
\text { F30-39 (mood disorder) } \\
\text { F10-19 (substance misuse) } \\
\text { F60-69 (personality disorder) } \\
\text { All other diagnostic categories }\end{array}$ & $\begin{array}{c}58 \\
24 \\
4 \\
3 \\
\text { Each }<2 \%\end{array}$ & $\begin{array}{c}61 \\
22 \\
3 \\
4 \\
\text { Each }<2 \%\end{array}$ \\
\hline $\begin{array}{l}\text { Ward type, \% } \\
\quad \text { General acute } \\
\text { Psychiatric intensive care }\end{array}$ & $\begin{array}{l}93 \\
7\end{array}$ & $\begin{array}{c}93 \\
7\end{array}$ \\
\hline $\begin{array}{l}\text { Mental Health Act status, \% } \\
\text { Formal }\end{array}$ & 49 & 51 \\
\hline $\begin{array}{l}\text { Duration of current admission, \% } \\
\text { Longer than } 6 \text { weeks }\end{array}$ & 53 & 55 \\
\hline
\end{tabular}


Table 2 Performance against the audit standards in the total national sample at baseline and re-audit

\begin{tabular}{|lcccccc} 
& \multicolumn{2}{c}{ Baseline $(n=3492)$} & & \multicolumn{2}{c}{ Re-audit $(n=3271)$} \\
\cline { 2 - 3 } Standard & $\begin{array}{c}\text { Standard met } \\
n(\%)\end{array}$ & $\begin{array}{c}\text { Standard not met } \\
n(\%)\end{array}$ & & $\begin{array}{c}\text { Standard met } \\
n(\%)\end{array}$ & $\begin{array}{c}\text { Standard not met } \\
n(\%)\end{array}$ \\
\hline A standard dose should be prescribed & $2227(63.8)$ & $1265(36.2)$ & & $2151(65.8)$ & $1120(34.2)$ \\
\hline A single antipsychotic should be prescribed & $1991(57)$ & $1501(43)$ & & $1984(60.7)$ & $1287(39.3)$ \\
\hline FGAs and SGAs should not be co-prescribed & $2403(68.8)$ & $1089(31.2)$ & & $2335(71.4)$ & $936(28.6)$ \\
\hline FGA, first-generation antipsychotic; SGA, second-generation antipsychotic. & & & \\
\hline
\end{tabular}

The binary logistic regression analysis of the baseline audit data with 'high dose' as the dependent variable found that, together, combined antipsychotics, age band, ward type, Mental Health Act status and gender correctly predicted the prescription of high dose or not high dose in $82 \%$ of cases. The only variable in this model that was significant at the level of $P<0.001$ was 'combined antipsychotics'. A patient who was prescribed combined antipsychotics was more than 20 times more likely to be prescribed a high dose as defined in our audit than a patient who was prescribed a single antipsychotic (odds ratio $(\mathrm{OR})=23,95 \%$ CI 18-29). The regression analysis was repeated after removing the combined antipsychotics variable, in order to examine further the possible influence of the other variables. This model was relatively poor at predicting high dose or not high dose, yielding only $60 \%$ correct classifications. Adding ethnicity to the model did not improve its predictive power. Similar results were obtained when the analysis was repeated using the data from the 1-year audit. On this occasion, combined antipsychotics, age band, ward type, Mental Health Act status and gender together predicted the prescription of high dose or not high dose in $81.5 \%$ of cases. The only variables in this model that were significant at the level of $P<0.001$ were combined antipsychotics and Mental Health Act status. Again, adding ethnicity to the model did not improve its predictive power. As at baseline, a patient who was prescribed combined antipsychotics was more than 20 times more likely to be prescribed a high dose as defined in our audit than a patient who was prescribed a single antipsychotic $(\mathrm{OR}=20.8,95 \% \mathrm{CI}$ $16.1-26.3)$.

\section{Discussion}

We found a high prevalence for the prescription of both high-dose and combined antipsychotics in adult in-patient settings in the UK. Only a small proportion of this was consistent with

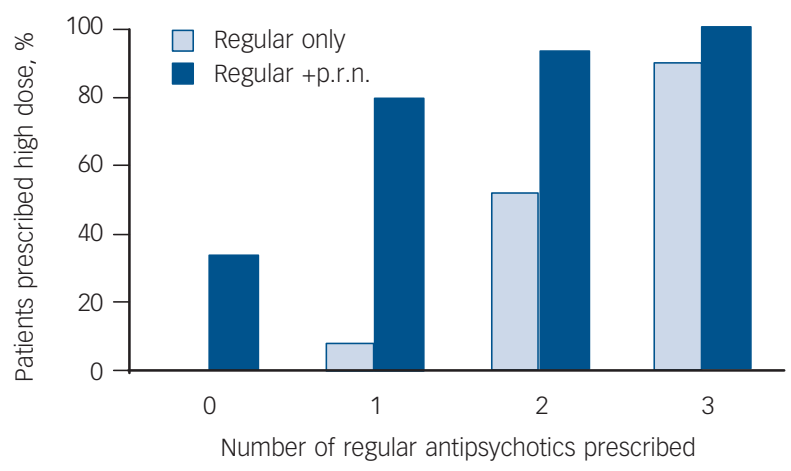

Fig. 1 Effect of pro re nata (p.r.n.) medication on high-dose prescribing: re-audit data. recommended treatment strategies such as cross-titration when switching from one antipsychotic to another, or augmentation of clozapine. Most was due to p.r.n. prescribing of antipsychotic drugs for the management of behavioural disturbance. Thus, prescribing practice fell well below the audit standards derived from the recommendations made in clinical guidelines. Although the use of combined antipsychotics significantly predicted high dosage, none of the other demographic and clinical variables collected in the audits did so. This included ethnicity, a finding that is consistent with Connolly et al. ${ }^{12}$ Our quality improvement interventions, designed to encourage reflective practice and based on methods known to produce change, had little impact within the year to re-audit (see online Table DS1).

We propose three possible explanations for the failure of our quality improvement programme to change practice. First, the standards might not have been accepted by those to whose practice they relate. Second, the change interventions might not have reached - or, if they did reach, might not have influenced - those for whom they were intended; in allowing trusts to determine their own strategies for implementing interventions, it is likely that there was variation in the way the interventions were disseminated and used. Third, there might be cultural or organisation system factors that hindered change. We suspect that all three contributed and that the most important common element was p.r.n. prescribing.

We did not measure changes in the staff or patient group from baseline to re-audit. However, there is considerable consistency of practice across the UK regarding staffing and use of acute psychiatric wards. This allows some assumptions to be made with confidence. Although there would have been relatively little change in the senior medical or nursing staff, most wards would have had different junior doctors at baseline and re-audit, and the patient cohort would have changed greatly. Thus, the relative stability of the prevalence of p.r.n. prescribing over the period of our audit cycle suggests that such practice is not due to transient factors such as a particularly challenging group of patients at the time of the audit census or the prescribing practice of a particular cohort of junior doctors.

Pro re nata prescribing of antipsychotic drugs is neither supported by a robust evidence base demonstrating effectiveness and safety, ${ }^{13}$ nor routinely covered by institutional policies, procedures or guidelines, ${ }^{14}$ yet is common in psychiatric in-patient settings. ${ }^{15,16}$ Most patients who have a diagnosis of schizophrenia or mania have at least one dose of p.r.n. antipsychotic administered during their hospital stay. ${ }^{15}$ The risk of a patient being given a high dose may not be recognised by either the prescribing doctor or the administering nurse. In addition, several studies have found that neither the therapeutic outcome nor the side-effect burden after p.r.n. antipsychotics is adequately documented in medical records, ${ }^{15,16}$ which means that clinical teams may continue with this approach without the ability to systematically evaluate its risks and benefits. 
The 'custom and practice' of p.r.n. prescribing within clinical teams leads to a loss of clarity regarding responsibility. ${ }^{17}$ Although p.r.n. medication is usually prescribed by junior doctors, it is strongly influenced by the requests of ward-based nurses for access to additional medication. ${ }^{18}$ Previous studies suggest that a large proportion of p.r.n. prescriptions do not contain clear indications for use or frequency of administration. ${ }^{19}$ The same dose may be prescribed by the oral or intramuscular route, and the use of dose ranges is common. ${ }^{20}$ Thus, the choice of p.r.n. dose, route, frequency and indication may be left to the nursing staff. Some data indicate that the reasons for administration may differ from those intended. For example, where both benzodiazepines and antipsychotics are prescribed p.r.n., nursing staff preferentially administer the antipsychotic, ${ }^{21,22}$ whereas doctors prefer the use of benzodiazepines for most indications. ${ }^{22}$ Nurses identify more indications for the use of p.r.n. antipsychotics than do doctors, notably for the acute management of hallucinations, delusions and thought disorder, and their preferred antipsychotics are haloperidol and chlorpromazine. ${ }^{22}$ Concerns have been raised that nurses do not have enough knowledge of psychopharmacology to make appropriate choices from a range of p.r.n. options and to monitor for side-effects, ${ }^{23}$ and research in this area has been considered a priority. ${ }^{24}$

There is some evidence that patients who receive p.r.n. antipsychotics have an increased burden of side-effects, particularly sedation, confusion, extrapyramidal side-effects and postural hypotension, ${ }^{15}$ and are at greater risk of clinically significant drug interactions. ${ }^{25}$ In addition, we found that p.r.n. prescribing commonly led to co-prescription of first- and second-generation antipsychotics, which is likely to negate the main advantage of the newer drugs, that being their lower liability to cause extrapyramidal side-effects. This is supported by the findings of a large survey of prescribing practice: patients prescribed combined firstand second-generation antipsychotics were just as likely to be prescribed anticholinergic agents as patients prescribed firstgeneration drugs alone. ${ }^{16}$ Further, the majority of antipsychotics have some potential to prolong the cardiac $\mathrm{QT}_{\mathrm{c}}$ interval, an effect that may rarely result in serious cardiac arrhythmias. In 2006, the Medicines and Healthcare Regulatory Authority conducted a review of the cardiac safety of all antipsychotic drugs available in the UK. ${ }^{26}$ This led to the recommendation that the wording 'avoid concomitant neuroleptics' should be added to the 'special warnings and precautions for use' section of the summary of product characteristics (product licence) of every antipsychotic; the routine prescription of antipsychotics on a p.r.n. basis is in contrast to the caution that is recommended.

\section{Strategies to reduce the use of p.r.n. prescribing}

Our audit findings support the notion that p.r.n. antipsychotic medication is an embedded practice in many in-patient clinical teams, which leads to high-dose and combined antipsychotic prescribing and seems to be resistant to educational change interventions. However, small studies have demonstrated that interventions that integrate the use of p.r.n. medication into a care pathway can significantly reduce prescribing and administration. Examples include standard setting ${ }^{20}$ and the use of stat (immediate) doses in place of p.r.n. ${ }^{27}$ Further, studies have demonstrated that senior nursing staff are able to identify more alternatives to p.r.n. than junior or part-time staff, ${ }^{22}$ and that mandatory review of patients receiving p.r.n. by staff with specialist skills in behavioural management and psychopharmacology reduced the subsequent use of p.r.n. medication. ${ }^{28}$ Simple strategies such as the provision of structured daytime activities can also be effective. ${ }^{28}$
Carol Paton, Oxleas NHS Foundation Trust, Dartford; Thomas R. E. Barnes Department of Psychological Medicine, Imperial College, London; Mary-Rose Cavanagh, David Taylor, South London and Maudsley NHS Trust, London; Paul Lelliott, Royal College of Psychiatrists Research Unit, London, UK, on behalf of the Prescribing Observatory for Mental Health project team

Correspondence: Carol Paton, Chief Pharmacist, Oxleas NHS Foundation Trust, Pinewood House, Pinewood Place, Dartford, Kent DA2 7WG, UK. Email: C.Paton@imperial.ac.uk

First received 11 Jul 2007, final revision 12 Nov 2007, accepted 11 Dec 2007

\section{Acknowledgements}

Acknowledgements are due to the Health Foundation which funded the UK Prescribing Observatory for Mental Health (POMH-UK) with a tapering grant from 2005, the local POMH-UK project teams of the participating services and the National Health Service clinicians and administrators who collected the audit data, and Dr Andy Thompson and Simon Strange who acted as advisors. In addition to the authors, the members of the Topic 1 project group were Janey Antoniou, Elizabeth Hancock and Mo Hutchison.

\section{References}

1 Centorrino F, Goren JL, Hennen J, Salvatore P, Kelleher JP, Baldessarini RJ. Multiple versus single antipsychotic agents for hospitalised psychiatric patients: case-control study of risks versus benefits. Am J Psychiatry 2004; 161: 700-6

2 Harrington M, Lelliott C, Paton C, Ochoka C, Duffett R, SenskyT. The results of a multi-centre audit of the prescribing of antipsychotic drugs for inpatients in the UK. Psychiatr Bull 2002; 26: 414-18.

3 Joukamaa M, Heliovaara M, Knekt P, Aromaa A, Raitasalo R, Lehtinen V. Schizophrenia, neuroleptic medication and mortality. Br J Psychiatry 2006; 188: $122-7$.

4 National Institute for Clinical Excellence. The Treatment and Management of Schizophrenia in Primary and Secondary Care (Core Interventions). NICE, 2003.

5 Herz Ml, Liberman RP, Lieberman JA, Marder SR, McGlashan TH, Wyatt RJ, Wang P. Practice guideline for the treatment of patients with schizophrenia. Am J Psychiatry 1997; 154 (suppl 4): 1-63.

6 De Hert M, Wampers M, Peuskens J. Pharmacological treatment of hospitalised schizophrenic patients in Belgium. Int J Psychiatry Clin Pract 2006; 10: 285-90.

7 Royal College of Psychiatrists. Revised Consensus Statement on High Dose Antipsychotic Medication (Council Report CR138). Royal College of Psychiatrists, 2006.

8 National Institute for Clinical Excellence. Guidance on the Use of Newer (Atypical) Antipsychotic Drugs for the Treatment of Schizophrenia. Health Technology Appraisal Guidance 43. NICE, 2006.

9 World Health Organization. International Statistical Classification of Diseases and Related Health Problems (ICD-10). WHO, 1992.

10 Iles V, Sutherland K. Organisational Change: A Review for Healthcare Managers, Professionals and Researchers. National Coordinating Centre for Service Delivery and Organisation, 2001.

11 Lelliott $\mathrm{P}$, Paton $\mathrm{C}$, Harrington $\mathrm{M}$, Konsolaki M, Sensky $T$, Okocha $C$. The influence of patient variables on polypharmacy and combined high dose of antipsychotic drugs prescribed for in-patients. Psychiatr Bull 2002; 26: 411-14.

12 Connolly A, Rogers P, Taylor D. Antipsychotic prescribing quality and ethnicity - a study of hospitalized patients in south east London. J Psychopharmacol 2007; 21: 191-7.

13 Whicher $E$, Morrison $M$, Douglas-Hall P. 'As required' medication regimens for seriously mentally ill people in hospital (review). Cochrane Database of Systematic Reviews, issue 3, CD003441. Update Software, 2002.

14 Szczesny S, Miller M. PRN medication in inpatient psychiatry. J Psychosoc Nurs Ment Health Serv 2003; 41: 16-21.

15 Geffen J, Sorensen L, Stokes J, Cameron A, Roberts MS, Geffen L, Pro re nata medication for psychoses: an audit of practice in two metropolitan hospitals. Aust N Z J Psychiatry 2002; 36: 649-56.

16 Paton C, Lelliott P, Harrington M, Okocha C, Sensky T, Duffet R. Patterns of antipsychotic and anticholinergic prescribing for hospital inpatients. J Psychopharmacol 2003; 17: 223-9.

17 Baker JA, Lovell K, Harris N. Mental health professionals' psychotropic pro re nata (p.r.n.) medication practices in acute inpatient mental health care: a qualitative study. Gen Hosp Psychiatry 2007; 29: 163-8. 
18 Ito $H$, Koyama A, Higuchi T. Polypharmacy and excessive dosing psychiatrists' perceptions of antipsychotic drug prescription. Br J Psychiatry 2006; 187: 243-7.

19 Craven JL, Voore PM, Voineskos G. PRN medication for psychiatric inpatients. Can J Psychiatry 1987; 32: 199-203.

20 Bowden MF. Audit: prescription of 'as required' (p.r.n.) medication in an in-patient setting. Psychiatr Bull 1999; 23: 413-16.

21 Usher K, Luck L. Psychotropic PRN: a model for best practice management of acute psychotic behavioural disturbance in inpatient psychiatric settings. Int $J$ Mental Health Nursing 2004; 13:18-21.

22 Geffen J, Cameron A, Sorensen L, Stokes J, Roberts MS, Geffen L. Pro re nata medication for psychoses: the knowledge and beliefs of doctors and nurses. Aust N Z J Psychiatry 2002; 36: 642-8.

23 Brooker C, Falloon I, Butterworth A, Goldberg D, Graham-Hole V, Hillier V. The outcome of training community psychiatric nurses to delive psychosocial intervention. Br J Psychiatry 1994; 165: 222-30.

24 Usher K, Holmes C, Lindsay D, Lack L. PRN psychotropic medications: the need for nursing research. Contemp Nurse 2003; 14: 248-57.
25 Davies SJ, Lennard MS, Ghahramani P, Pratt P, Robertson A, Potokar J. PRN prescribing in psychiatric inpatients - potential for pharmacokinetic drug interactions. J Psychopharmacol 2007: 21: 153-60.

26 Medicine and Healthcare Regulatory Authority. Pharmacovigilance Working Party Public Assessment Report on Neuroleptics and Cardiac Safety, in particular OT prolongation, cardiac arrhythmias, ventricular tachycardia and torsades de pointes. MHRA (www.mhra.gov.uk/home/groups/pl-p/ documents/websiteresources/con2024041.pdf).

27 Thapa PB, Palmer SL, Owen RR, Huntley AL, Clardy JA, Miller LH. PRN (as needed) orders and exposure of psychiatric inpatients to unnecessary psychotropic medications. Psychiatr Serv 2003; 54: 1282-6.

28 Donat DC. Impact of a clinical-administrative review procedure on reducing reliance on psychotropic PRN medication. Psychiatr Rehab J 2006; 29 215-18.

29 Donat DC. Encouraging alternatives to seclusion, restraint, and reliance on PRN drugs in a public psychiatric hospital. Psychiatr Serv 2005; 56 : $1105-8$.

\section{psychiatry in pictures}

\section{Military psychiatry at the Maudsley, 1918}

Researched by Lieutenant Colonel Mark Tarn, and Professor Edgar Jones.

This remarkable picture captures the closure of the first great chapter in the history of British military psychiatry. Taken in December 1918, it shows a group of Army doctors photographed in front of the main entrance to the Maudsley Hospital. The Maudsley, constructed in 1915 to treat civilian psychiatric disorders, was actually opened in January 1916 as a specialist treatment and research hospital for 'shell shock'. Seated, front left and front right, are two luminaries of the time: William Rivers and Frederick Mott.

Mott, the leading neuropathologist of his age, was biologically minded. He believed that the clinical manifestations of shell shock were brought about by small, pathological changes in the central nervous system, caused by close proximity to explosions or toxins. His subsequent experiences led him to modify these views and recognise a psychological component.

Rivers had been a lecturer at Cambridge in medical psychology; he was also a renowned anthropologist. He believed Freud's ideas could be used to understand war neuroses. Famously, in 1917, he treated the war poet Siegfried Sassoon at the Craiglockhart Hospital near Edinburgh. As a result, Sassoon returned to active duty as an infantry officer in France.

Lessons learnt in military psychiatry are often forgotten once the conflict has been resolved. One wonders what Mott and Rivers would have thought of the current phenomenon of 'minor traumatic brain injury' currently described in American veterans of Iraq and Afghanistan.

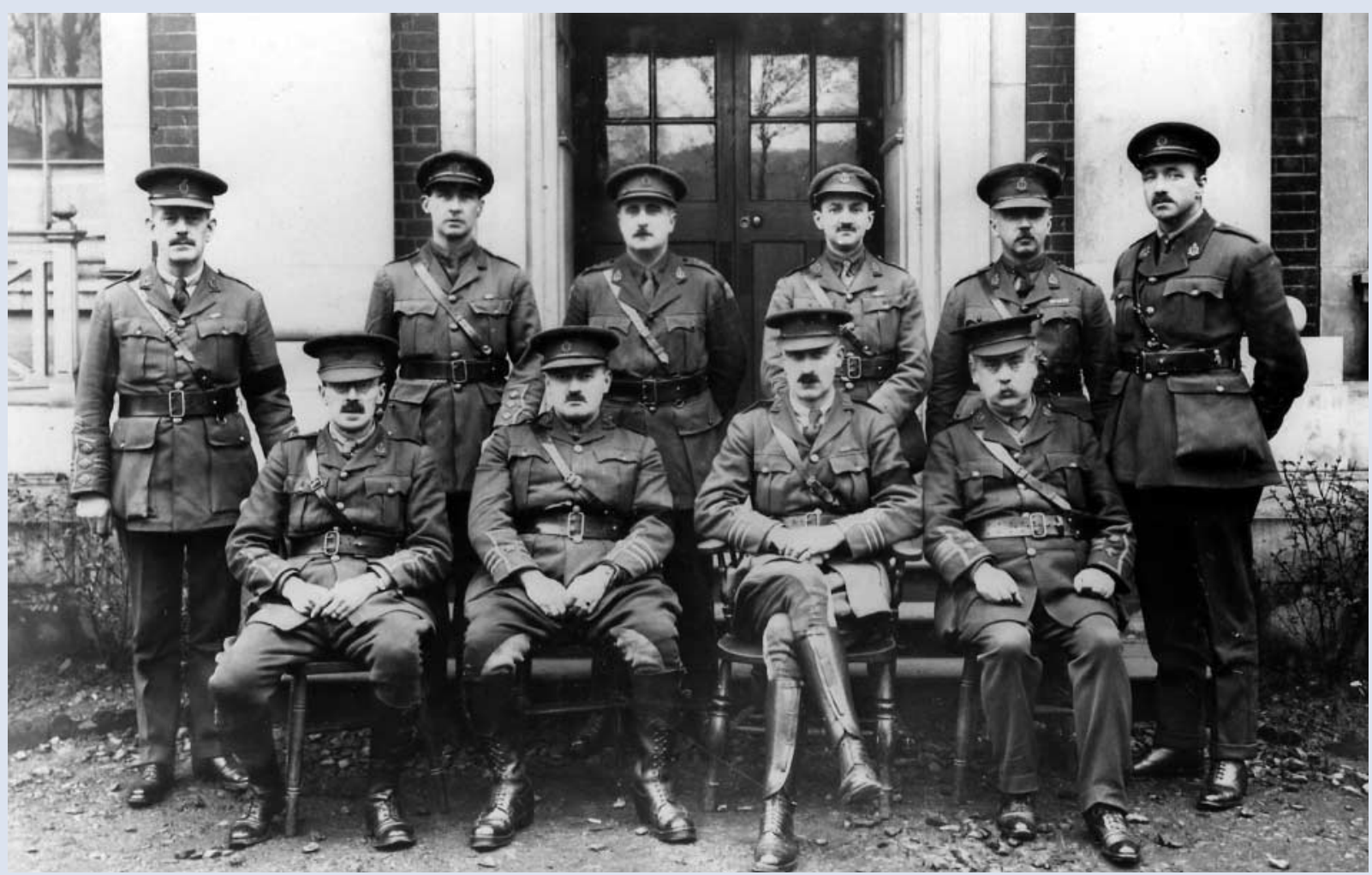

Photograph courtesy of the Bethelm Royal Archives and Museum. 